\title{
The effects of dietary advice and vouchers on the intake of fruit and fruit juice by pregnant women in a deprived area: a controlled trial
}

\author{
ML Burr ${ }^{1, *}$, J Trembeth ${ }^{2}$, KB Jones ${ }^{3}$, J Geen ${ }^{3}$, LA Lynch ${ }^{4}$ and ZES Roberts ${ }^{1}$ \\ 'Department of Epidemiology, Statistics and Public Health, Centre for Health Sciences Research, \\ Cardiff University, Neuadd Meirionnydd, Heath Park, Cardiff CF14 4YS, UK: \\ ${ }^{2}$ Nutrition and Dietetics Department, Torbay Hospital, Torbay, UK: ${ }^{3}$ Clinical Biochemistry Department, \\ Prince Charles Hospital, Merthyr Tydfil, UK: ${ }^{4}$ Maternity Department, Prince Charles Hospital, Merthyr Tydfil, UK
}

Submitted 18 April 2005: Accepted 11 April 2006: First published online 7 March 2007

\begin{abstract}
Objective: To examine the effectiveness of two methods of increasing fruit and fruit juice intake in pregnancy: midwives' advice and vouchers exchangeable for juice. Design: Pregnant women were randomly allocated to three groups: a control group, who received usual care; an advice group, given advice and leaflets promoting fruit and fruit juice consumption; and a voucher group, given vouchers exchangeable for fruit juice from a milk delivery firm. Dietary questionnaires were administered at $\sim 16$, 20 and 32 weeks of pregnancy. Serum $\beta$-carotene was measured at 16 and 32 weeks. Setting: An antenatal clinic in a deprived area.

Subjects: Pregnant women aged 17 years and over.

Results: The study comprised 190 women. Frequency of fruit consumption declined during pregnancy in all groups, but that of fruit juice increased substantially in the voucher group. Serum $\beta$-carotene concentration increased in the voucher group, from 106.2 to $141.8 \mu \mathrm{moll}^{-1}$ in women with measurements on both occasions $(P=0.003)$, decreased from 120.0 to $99.8 \mu \mathrm{moll}^{-1}$ in the control group $(P=0.005)$, and was unchanged in the advice group.

Conclusions: Pregnant women drink more fruit juice if they receive vouchers exchangeable for juice supplied by the milk delivery service. Midwives' advice to eat more fruit has no great effect. Providing vouchers for fruit juice is a simple method of increasing its intake in a deprived population and may be useful for other sections of the community.
\end{abstract}

\author{
Keywords \\ Dietary advice \\ Fruit \\ Fruit juice \\ Pregnancy
}

There is a growing body of evidence on the importance of fruit and vegetables in maintaining health. The benefits seem to include favourable effects on lung function ${ }^{1,2}$, respiratory symptoms ${ }^{1}$, blood pressure ${ }^{3}$, heart disease ${ }^{4}$, stroke $^{5}$ and cancer incidence ${ }^{6}$, and operate throughout childhood and adult life. In consequence, the Department of Health and other official bodies recommend that people should eat at least five portions of fruit and vegetables daily, one of which can be in the form of fruit juice ${ }^{7}$.

Only a small minority of the population (15\% of women) achieve the recommended intake of fruit and vegetables $^{8}$. People of lower socio-economic status are particularly liable to have inadequate consumption of these foods? ${ }^{9}$, which probably contributes to their high morbidity and mortality rates. It is therefore important to investigate methods of increasing the uptake of these foods in the more deprived communities.

A randomised controlled trial was set up in a deprived area to see whether the intake of fruit or fruit juice by pregnant women could be increased using two alternative methods: advice from the midwife and vouchers exchangeable for fruit juice supplied by a milk delivery firm.

\section{Subjects and methods}

The area selected for the study is one of the most deprived in Wales, in terms of long-term deprivation and poverty; furthermore, for 1990-1995, it had the highest agestandardised mortality rate in Wales for both males and females ${ }^{10}$. The study was directed to pregnant women for the following reasons:

1. Adequate nutrition is particularly important during pregnancy; there is evidence that antenatal nutrition has lifelong health effects on the unborn child ${ }^{11}$.

2. Young mothers are key individuals in influencing the diet of the population, in that they largely determine 
the food intake of their children and to some extent of their partners.

3. They have regular contact with health service personnel.

4. It might be expected that they would be more receptive to health-related advice than other members of the community.

The aims of the study were:

1. To see whether dietary advice given by midwives increases the intake of fresh fruit in pregnancy.

2. To see whether the intake of fruit juice by pregnant women is increased by the issue of vouchers exchangeable for fruit juice supplied by the milk delivery service.

Fruit and fruit juice rather than vegetables were selected for these interventions because they do not require cooking, so that their intake can be more easily increased.

Pregnant women attending the booking clinic at a district general hospital were invited to participate in the study if they were at least 17 years old and booked under the care of one of the consultant obstetricians at that hospital. An information sheet explaining the study was sent to the women before they attended the booking clinic so as to give them the opportunity to reflect on whether they wished to participate and reduce the length of time needed to explain the study at the clinic. There they were interviewed, and the study was explained in more detail. Women were excluded from the trial if they had diabetes or did not expect to reside within the area supplied by the milk delivery firm throughout the pregnancy.

A short questionnaire was administered to the women who agreed to participate. They were asked to state how often they usually took various foods, and were offered nine frequencies: never, rarely (less than once a week), and 1-7 days per week. The specified foods included apples/pears, oranges/satsumas/tangerines, bananas, grapefruit, peaches/plums, grapes/berries, other fresh fruit, tinned fruit, 'pure 100\% fruit juice (not squash or fizzy drinks)' and vegetables other than potatoes. The questionnaire was based on one that was previously used in the same area among elderly people, which showed the frequency of fresh fruit intake to be significantly associated with plasma ascorbate concentration $^{12,13}$; the questionnaire in this study differed in that it enquired about separate categories of fruit, since we wished to examine changes in different fruits.

The women were then allocated to three groups, by means of cards designating these groups that were placed in random order within serially numbered opaque sealed envelopes:

1. Control group. Women in this group received usual care, including any dietary advice normally given from midwives, health visitors, general practitioners, etc.

2. Advice group. Women in this group received advice and written information from the midwife about increasing the amount of fruit and fruit juice in their diet. A leaflet was issued describing the health benefits of fruit in pregnancy, suggesting various ways of increasing the intake of fruit and fruit juice, and giving advice about how to buy fruit cheaply.

3. Voucher group. Women in this group received vouchers to be exchanged for free cartons of pure fruit juice delivered directly to the door by the local milk delivery service. The amount of fruit juice supplied to each pregnant women in this group was 21 per week for $\sim 30$ weeks.

The midwives were given oral and written details about the purpose and rationale of the study, including information about the health benefits of fruit and the sources and actions of vitamin $\mathrm{C}$ and $\beta$-carotene.

The vouchers were numbered individually and issued in batches to the appropriate women, who were asked to write their addresses on them. The milk delivery company was informed of each address where juice (100\% orange juice) was to be delivered, the vouchers being accepted as payment only for this product. Further batches of vouchers were supplied to these women as required.

The dietary questionnaire was repeated at $\sim 20$ weeks of pregnancy (by post or telephone) and again at $\sim 32$ weeks at interview, when the women had another antenatal hospital appointment. The baseline and later questionnaires were compared for each individual so as to see whether fruit intake had changed. A rise of two or more of the nine frequencies from baseline was considered as an increase; a fall of two or more frequencies was considered as a decrease. The net percentage of women whose intake of each fruit increased (i.e. the number of women whose intake increased minus the number whose intake decreased, expressed as a percentage of all women for whom information was available on both occasions) was calculated for the three groups. The differences between the groups was expressed as the net percentage increase in one group minus that in another, with 95\% confidence intervals (CIs) calculated by the method of squaring and adding ${ }^{14}$.

The women in the advice group were sent additional follow-up questionnaires asking whether certain problems stopped them eating more fruit: cost; changes in taste or appetite during pregnancy; disliking the taste of fruit; difficulties in preparation; fruit going rotten; nonavailability in local shops; difficulty in carrying it from the shops; family members disliking fruit; any other reason. Women in the voucher group were sent additional questionnaires asking whether they were receiving the free juice, and, if so, who in the household drank it and whether any was thrown away.

About $7 \mathrm{ml}$ of extra blood was obtained at $\sim 16$ and 32 weeks, when blood was routinely taken as part of antenatal care. Samples were protected from light prior to 
centrifugation; the serum was stored at $80^{\circ} \mathrm{C}$ until analysis, and then defrosted in the dark and protected from light during the carotene extraction procedure by using dark coloured reaction cups. The assay was subject to appropriate calibration and internal quality procedures. Serum $\beta$-carotene was measured as an objective biomarker of the intake of fruit and fruit juice, using reversed phase high-perfomance liquid chromatography and single wavelength ultraviolet detection at $453 \mathrm{~nm}$ (Chromosystems Instruments and Chemicals $\mathrm{GmbH}$ ). The reference range for this assay ${ }^{15}$ is $40-322 \mathrm{ng} \mathrm{ml}^{-1}$.

The paired $t$-test was used to determine whether there were significant changes in $\beta$-carotene levels between baseline and 32 weeks within each of the groups. A Tukey multiple comparisons test was used to determine whether there were significant differences in the changes in $\beta$-carotene levels between pairs of the groups. The number of women ultimately recruited was opportunistic; some of the assumptions on which a power calculation was based turned out to be incorrect.

The approval of the Local Research Ethics Committee was obtained for this study. Each woman gave signed consent to participate before recruitment.

\section{Results}

Out of 192 women who were invited to take part in the study, 190 agreed to participate; 64 were randomly allocated to the control group, 63 to receive advice and 63 to receive vouchers. Table 1 shows the baseline characteristics of the three groups; they were fairly similar except for a lower proportion of smokers in the advice group, and more first pregnancies in the voucher group.

Figure 1 shows the distribution of the women in the three groups according to the number of days per week on which they ate certain fruits and fruit juice at baseline, in three broad frequencies $\left(<2,2-4\right.$ and 5-7 days week $\left.{ }^{-1}\right)$. The fresh fruits most commonly eaten were apples or pears, oranges and similar citrus fruits, and bananas. The other categories of fruit were not commonly eaten in this population $(<10 \%$ overall ate any of these types of fruit on 5 or more days weekly), and their consumption tended to decline during pregnancy in all groups, except for that of canned fruit, which rose slightly in all groups. The data on these fruits are therefore not presented here.
A substantial proportion of the women ( $37 \%$ overall) said that they drank 'pure $100 \%$ fruit juice' on 5-7 days weekly. An attempt was made to distinguish between pure fruit juice and squash or other drinks, but it cannot be assumed that all these women understood this distinction. The pattern of fruit consumption was fairly similar in the three groups at baseline; vegetable consumption (not shown) was very similar in the three groups.

Table 2 shows the mean serum $\beta$-carotene concentrations of the women at baseline, in the same three broad intake frequencies for each fruit. In each case, the serum $\beta$-carotene tended to rise with increasing frequency of intake; the high standard deviations reflect the skewed distribution, but median values (not shown) displayed a very similar pattern. Spearman's rank correlation coefficient was calculated to examine the relationship between the intake of each item (using the nine frequencies) and serum $\beta$-carotene at baseline. The correlations, although rather weak, were highly significant for oranges and fruit juice, and approached statistical significance for apples and bananas. A similar gradient was seen in relation to vegetable intake; the correlation just fell short of statistical significance ( $r=0.15, P=0.053)$.

Table 3 shows the net percentage of women whose intake of each fruit increased. The consumption of apples, oranges and bananas had not greatly changed at 20 weeks, but by 32 weeks their intake showed an overall tendency to decline. Of the 39 women in the advice group who gave information at 32 weeks, the difficulties identifed were change in taste in 20, fruit going rotten (18), disliking the taste (four), non-availability (four), carrying the fruit (four), family members' dislike (two), cost (one), children eating it first (one); nobody saw food preparation as a problem.

A substantial and maintained increase of fruit juice intake occurred in the voucher group, in contrast to the decreases seen in the other groups. From the extra information received from the voucher group, it appeared that in a few cases the supply was interrupted or discontinued due to change of address; very little was thrown away. Of the 37 who continued to receive juice and provided information at 32 weeks, all claimed to drink it, although 25 shared it, mostly with children or partners.

Table 4 shows the serum $\beta$-carotene concentrations in all the women for whom it was measured at baseline, and in those for whom a repeat value was obtained at 32

Table 1 Baseline characteristics of women in the three randomised groups

\begin{tabular}{lccc}
\hline & Control group & Advice group & Voucher group \\
\hline Total number & 64 & 63 & 63 \\
Mean age in years (SD) & $25.5(5.7)$ & $26.4(5.4)$ & $24.5(5.1)$ \\
No. (\%) current smokers & $35(54.7)$ & $17(27.0)$ & $30(47.6)$ \\
No. (\%) first pregnancy & $17(26.6)$ & $17(27.0)$ & $25(39.7)$ \\
Mean (SD) week gestation & $16.0(3.1)$ & $15.6(2.3)$ & $16.1(2.6)$ \\
No. (\%) taking vitamins/minerals & $17(26.6)$ & $21(33.3)$ & $16(25.4)$ \\
\hline
\end{tabular}

SD - standard deviation. 

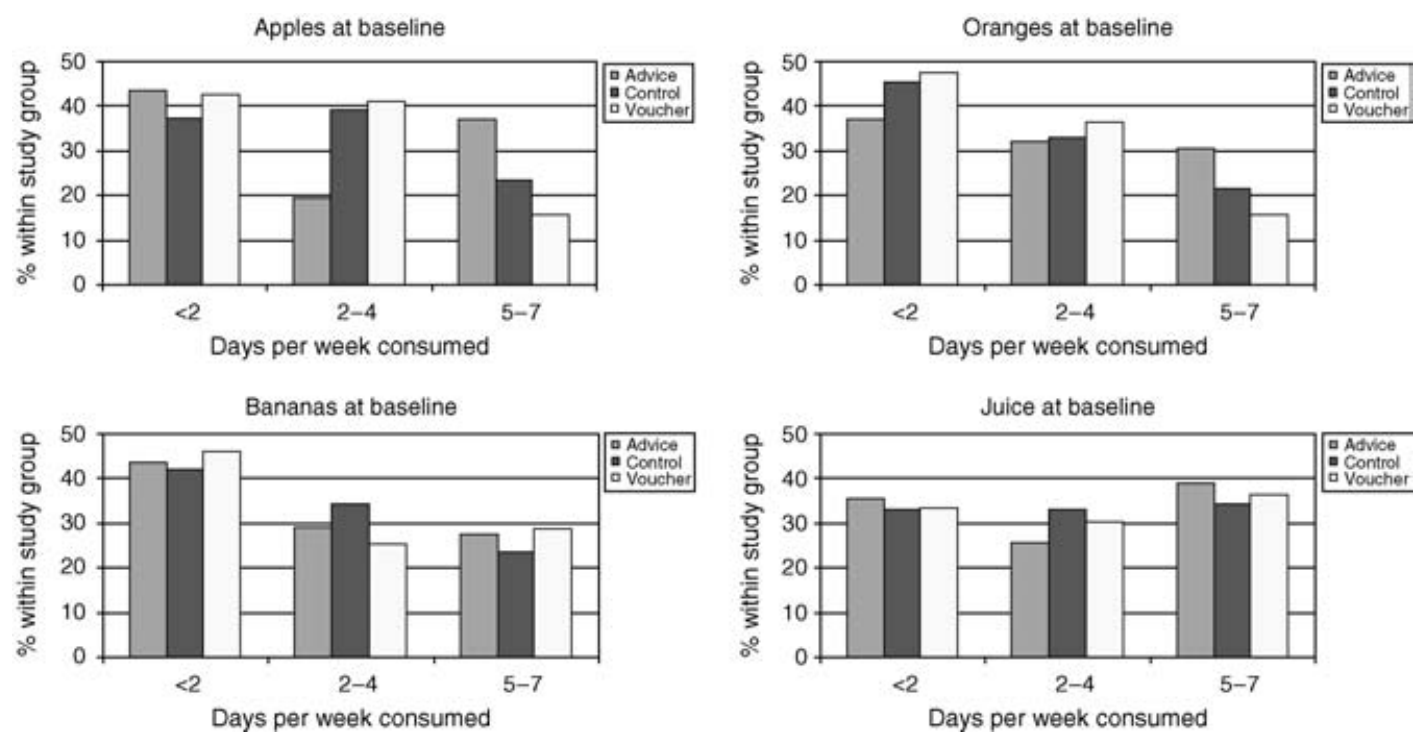

Fig. 1 Distribution of women at baseline according to fruit intake frequency, in three randomised groups

weeks. The women who provided both samples had very similar mean baseline values to those of the original randomised groups of which they formed part. When the changes were examined in the women who provided a second sample, there was a significant fall in the control group, a significant rise in the voucher group, and no change in the advice group. In view of the differences between the three groups regarding smoking status and parity, the relationship was examined between these characteristics and change in $\beta$-carotene. No significant differences were found between the changes in $\beta$-carotene in smokers and non-smokers, or between those in primigravida and multigravida, so no adjustments were made for these characteristics in the dietary or biochemical statistical analyses.

Table 5 shows the differences between the changes from baseline to 32 weeks in the randomised groups. For each fruit, the net percentage whose intake increased (defined as in Table 3) for one group was subtracted from that for another group. The 95\% CIs reveal no significant differences in respect of apples, oranges or bananas, but a significant increase in fruit juice consumption in the voucher group relative to the changes in the other groups. Serum $\beta$-carotene similarly increased significantly in the voucher group relative to the change in the advice group, and even more so relative to the change in the control group.

Vegetable intake (not shown) tended to decline in all groups; the differences between the groups in this regard were smaller than those for fruits and did not approach statistical significance.

The cost of the intervention was almost wholly that of the orange juice: $£ 75$ per person to supply juice for 30 weeks (£4725 overall); there were also small printing expenses for forms and vouchers, but no distribution costs.

\section{Discussion}

Eating fruit and vegetables seems to confer a wide range of benefits to health. It has been estimated that an increment of one serving per day reduces the risk of ischaemic stroke by $6 \% 5$ and an extra 1.5 portions reduces cancer risk by $23 \%{ }^{6}$. Other effects probably include enhancement of lung function $^{1,2}$ and protection against ischaemic heart disease ${ }^{4}$. Vitamin C intake in pregnancy is related to birth weight ${ }^{16}$, which has lifelong predictive implications for health ${ }^{11}$.

The potential benefit of increasing fruit intake is likely to be greatest in deprived areas, where fruit intake is lowest; the intake of fruit-related nutrients (fibre, carotene and

Table 2 Relationship between frequency of fruit intake with serum $\beta$-carotene concentration in $\mathrm{ng} \mathrm{m} \mathrm{^{-1 }}$ at baseline

\begin{tabular}{lccccc}
\hline & \multicolumn{4}{c}{ Mean (SD) serum $\beta$-carotene by intake frequency } & \\
\cline { 2 - 5 } & Total no. & $<2$ days/week & 2-4 days/week & $5-7$ days/week & \multirow{2}{*}{$r^{*}(P)$} \\
\hline Apples & 160 & $115.9(77.3)$ & $111.1(71.5)$ & $145.2(89.5)$ & $0.15(0.057)$ \\
Oranges & 160 & $102.0(66.0)$ & $137.0(86.1)$ & $137.0(86.6)$ & $0.22(0.004)$ \\
Bananas & 160 & $108.9(68.0)$ & $120.9(76.8)$ & $145.2(96.2)$ & $0.15(0.057)$ \\
Fruit juice & 160 & $105.2(74.4)$ & $120.6(85.9)$ & $136.3(76.7)$ & $0.21(0.007)$ \\
\hline
\end{tabular}

SD - standard deviation.

${ }^{*} r=$ Spearman's rank correlation coefficient: intake (nine frequencies) vs. $\beta$-carotene. 
Table 3 Changes in fruit consumption in the three randomised groups

\begin{tabular}{|c|c|c|c|c|c|c|}
\hline & \multicolumn{6}{|c|}{ Net percentage of women consuming more fruit since baseline* } \\
\hline & \multicolumn{2}{|c|}{ Control group } & \multicolumn{2}{|c|}{ Advice group } & \multicolumn{2}{|c|}{ Voucher group } \\
\hline & $\begin{array}{c}20 \text { weeks } \\
(n=42)\end{array}$ & $\begin{array}{c}32 \text { weeks } \\
(n=37)\end{array}$ & $\begin{array}{c}20 \text { weeks } \\
(n=44)\end{array}$ & $\begin{array}{c}32 \text { weeks } \\
(n=38)\end{array}$ & $\begin{array}{c}20 \text { weeks } \\
(n=45)\end{array}$ & $\begin{array}{c}32 \text { weeks } \\
(n=46)\end{array}$ \\
\hline Apples & 9.8 & -2.7 & 4.6 & -13.2 & 6.7 & 2.2 \\
\hline Oranges & 0 & -11.8 & -4.6 & -21.1 & 6.7 & -2.2 \\
\hline Bananas & -4.8 & -29.7 & 4.6 & -7.9 & -8.9 & -17.4 \\
\hline Fruit juice & 7.1 & -24.3 & 11.4 & -7.9 & 33.3 & 34.8 \\
\hline
\end{tabular}

* The number of women whose intake increased minus the number whose intake decreased, as a percentage of the number supplying information on both occasions.

Table 4 Serum $\beta$-carotene concentrations in $\mathrm{ng} \mathrm{ml}^{-1}$ in the three randomised groups

\begin{tabular}{lccc}
\hline & $\begin{array}{c}\text { Control group } \\
n, \text { mean (SD) }\end{array}$ & $\begin{array}{c}\text { Advice group } \\
n, \text { mean (SD) }\end{array}$ & $\begin{array}{c}\text { Voucher group } \\
n, \text { mean (SD) }\end{array}$ \\
\hline Baseline: all subjects & $57,115.9(70.8)$ & $54,139.5(87.3)$ & $53,110.7(76.4)$ \\
Baseline: subjects with 32 weeks data & $42,120.0(81.2)$ & $37,139.5(85.7)$ & $39,106.2(67.2)$ \\
32 weeks & $42,99.8(64.2)$ & $37,136.8(81.1)$ & $39,141.8(102.0)$ \\
Change* & $42,-20.2(43.3)$ & $37,-2.7(65.5)$ & $39,35.6(77.2)$ \\
$P$ for change & 0.004 & 0.81 & 0.007 \\
\hline
\end{tabular}

SD - standard deviation.

* The value at 32 weeks minus that at baseline in those women for whom both measurements were made.

Table 5 Differences between changes in randomised groups at 32 weeks

\begin{tabular}{lccc}
\hline & Voucher-control & Advice-control & Voucher-advice \\
\hline Difference in net percentage consuming more fruit* $(95 \% \mathrm{Cl})$ & & \\
Apples & $4.9(-22.5,31.9)$ & $-10.5(-39.0,19.2)$ & $15.3(-15.0,44.2)$ \\
Oranges & $8.6(-20.2,36.4)$ & $-10.2(-40.2,20.5)$ & $18.9(-9.0,44.8)$ \\
Bananas & $12.3(-14.5,37.5)$ & $21.8(-7.5,49.4)$ & $-9.5(-36.3,17.6)$ \\
Fruit juice & $59.1(29.3,84.1)$ & $16.4(-12.4,43.7)$ & $42.7(14.0,68.0)$ \\
Difference in mean change 32 & weeks-baseline, in $\mathrm{ng} / \mathrm{ml}(95 \% \mathrm{Cl})$ & \\
Serum $\beta$-carotene & $55.9(22.5,89.2)$ & $17.6(-16.2,51.3)$ & $38.3(3.9,72.7)$ \\
$P$ for difference & $<0.0001$ & 0.435 & 0.025 \\
\hline
\end{tabular}

$\mathrm{Cl}$ - confidence interval.

* Net percentage consuming more fruit defined as in the footnote to Table 3 .

vitamin C) among pregnant women is markedly related to their social class ${ }^{17}$. The difficulty lies in changing established dietary patterns in these communities. The present study was set up among women attending an antenatal clinic in a deprived area to examine the effects of two interventions: dietary advice by the midwife and vouchers exchangeable for pure orange juice from the milk delivery service. Pregnant women were selected partly because of their contact with health services and partly because of their importance in influencing the nutritional state of the community, directly and indirectly.

The answer to a simple question about frequency of fruit intake was related to plasma ascorbate in surveys of the elderly ${ }^{12,13}$ and to serum $\beta$-carotene in this study. Similar questions (using a telephone enquiry) were validated against detailed dietary information among diverse American populations ${ }^{18}$. It seems that the frequency of intake is more important than portion size in distinguishing between high and low consumption of fruit and vegetables ${ }^{19}$.

Brief dietary advice has been shown to elicit sustained increases in fruit and vegetable consumption and to raise plasma $\beta$-carotene concentration among adults in a deprived community ${ }^{20}$. The Department of Health encourages all health professionals to give advice on healthy living ${ }^{21}$, and midwives are well placed to do this. In this study, simple dietary advice did not overcome the tendency for fruit consumption to decline during pregnancy (except perhaps in relation to bananas and fruit juice); it may have prevented the decline in $\beta$-carotene seen in the control group, though the difference was not statistically significant. Even a small effect of this form of intervention is likely to be cost-effective; perhaps it should be investigated further in conjunction with specific dietary 
training of midwives, since they may lack the nutritional knowledge needed for effective dietary advice ${ }^{22}$.

The main barrier to increasing fruit intake was change in taste and appetite for fruit during pregnancy (identified by half the women), followed by the perishability of fruit. The availability and transport of fruit were less important issues, while cost was not perceived as a problem even in this deprived area.

Fruit juice has several biochemical and physiological effects that are likely to be beneficial to health. It enhances antioxidant status ${ }^{23-25}$, reduces lipoprotein oxidation ${ }^{26}$, reduces antioxidant DNA damage and stimulates immune cell function ${ }^{24}$; it also raises high-density lipoprotein cholesterol in people with hypercholesterolaemia ${ }^{27}$. It is considered to be easy to take $e^{28,29}$, and supplied $21 \%$ of the vitamin C intake of households in an American study ${ }^{30}$. It is thus a convenient and acceptable nutritional medium.

An American programme gives coupons exchangeable for certain fruits, vegetables and juices to families containing pregnant and postpartum women, and young children at risk of nutritional deficiency ${ }^{28}$. A comparative study (not randomised) examined the effects of education and vouchers among these families. The intake of fruit and vegetables was increased by issuing vouchers that were exchangeable at farmers' markets, and the effect was greater than that of education ${ }^{31}$. The use of milk delivery services in the present study has the advantage of regularly providing the fruit juice at the door. It also avoids the opportunity for redeeming the vouchers for other products that would be available at a supermarket. Fruit juice did not seem to replace fruit in the diet - at 32 weeks, changes in the fruit intake of the voucher group compared favourably with those of the control group (Table 5).

Serum $\beta$-carotene reflects fruit and vegetable intake $20,32-34$ and was therefore used as a biomarker of compliance. Although vegetables potentially supply more $\beta$-carotene than fruit, changes in their intake were very similar in the three groups, so their contribution is unlikely to have affected the results differentially. Ascorbate concentrations were unsuitable for this purpose owing to the presence of vitamin $\mathrm{C}$ in some of the supplements that are taken intermittently by pregnant women. The changes in $\beta$-carotene levels show that the pregnant women did indeed consume the juice; even when it was also drunk by other members of their households, these were within the same deprived community and likely to benefit from an increased intake.

The issue of vouchers in this way is thus a simple and effective method of increasing the intake of fruit juice among pregnant women in a deprived community. It is likely that it would also be useful in other sections of the population.

\section{Acknowledgements}

We thank the consultant obstetricians at Prince Charles Hospital for permission to involve their patients in this study, the midwives for giving the dietary advice, and Caron Sweeney for following up the patients and recording the data. We are grateful to the hospital dietitians for their advice and encouragement. The study was funded by a grant from Bro Taf Health Authority, which we gratefully acknowledge.

\section{References}

1 Cook DG, Carey IM, Whincup PH, Papacosta O, Chirico S, Bruckdorfer KR, et al. Effect of fresh fruit consumption on lung function and wheeze in children. Thorax 1997; 52: 628-33.

2 Butland BK, Fehily AF, Elwood PC. Diet, lung function, and lung function decline in a cohort of 2512 middle aged men. Thorax 2000; 55: 102-8.

3 Appel LJ, Moore TJ, Obarzanek E, Vollmer WM, Svetkey LP, Sacks FM, et al. A clinical trial of the effects of dietary patterns on blood pressure. New England Journal of Medicine 1997; 336: 1117-24.

4 Ness AR, Powles JW. Fruit and vegetables, and cardiovascular disease: a review. International Journal of Epidemiology 1997; 26: 1-13.

5 Feldman EB. Fruit and vegetables and the risk of stroke. Nutrition Reviews 2001; 59: 24-7.

6 World Cancer Research Fund, American Institute for Cancer Research. Food, Nutrition, and the Prevention of Cancer: A Global Perspective. Washington, DC: American Institute for Cancer Research, 1997.

7 Williams C. Healthy eating: clarifying advice about fruit and vegetables. British Medical Journal 1995; 310: 1453-5.

8 Henderson L, Gregory J, Swan G. The National Diet and Nutrition Survey: Adults Aged 19 to 64 Years. Vol. 1: Types and Quantities of Foods Consumed. London: The Stationery Office, 2002.

9 Billson H, Pryer JA, Nichols R. Variation in fruit and vegetable consumption among adults in Britain. An analysis from the dietary and nutrition survey of British adults. European Journal of Clinical Nutrition 1999; 53: 946-52.

10 Monaghan S. An Atlas of Health Inequalities Between Welsh Local Authorities. Cardiff: Bro Taf Health Authority, 1998.

11 Barker DJP, Eriksson JG, Forsén T, Osmond C. Fetal origins of adult disease: strength of effects and biological basis. International Journal of Epidemiology 2002; 31: 1235-9.

12 Burr ML, Elwood PC, Hole DJ, Hurley RJ, Hughes RE. Plasma and leukocyte ascorbic acid levels in the elderly. American Journal of Clinical Nutrition 1974; 27: 144-51.

13 Burr ML, Samloff IM, Bates CJ, Holliday RM. Atrophic gastritis and vitamin $\mathrm{C}$ status in two towns with different stomach cancer death-rates. British Journal of Cancer 1987; 56: $163-7$.

14 Newcombe RG. Improved confidence intervals for the difference between binomial proportions based on paired data. Statistics in Medicine 1998; 17: 2635-50.

15 Krapf FE. LaborDatenBuch. Munich: Urban and Schwarzenberg, 1995.

16 Mathews F, Yudkin P, Neil A. Influence of maternal nutrition on outcome of pregnancy: prospective cohort study. British Medical Journal 1999; 319: 339-43.

17 Haste FM, Brooke OG, Anderson HR, Bland JM, Griffin J, Peacock JL. Nutrient intakes during pregnancy: observations on the influence of smoking and social class. American Journal of Clinical Nutrition 1990; 51: 29-36.

18 Serdula M, Coates R, Byers T, Mokdad A, Jewell S, Chávez N, et al. Evaluation of a brief telephone questionnaire to estimate fruit and vegetable consumption in diverse study populations. Epidemiology 1993; 4: 455-63. 
19 Ashfield-Watt PAL, Welch AA, Day NE, Bingham SA. Is 'fivea-day' an effective way of increasing fruit and vegetable intakes? Public Health Nutrition 2003; 7: 257-61.

20 Steptoe A, Perkins-Porras L, Rink E, Hilton S, Cappucio FP. Behavioural counselling to increase consumption of fruit and vegetables in low income adults: randomised trial. British Medical Journal. 2003; 326: 855-8.

21 Department of Health. Our Healthier Nation: A Contract for Health. London: The Stationery Office, 1998.

22 Mulliner CM, Spiby H, Fraser RB. A study exploring midwives' education in, knowledge of and attitudes to nutrition in pregnancy. Midwifery 1995; 11: 37-41.

23 Young F, Nielsen SE, Haraldsdóttir J, Danshvar B, Lauridsen ST, Knuthsen $\mathrm{P}$, et al. Effect of fruit juice on urinary quercetin excretion and biomarkers of antioxidative status. American Journal of Clinical Nutrition 1999; 69: 87-94.

24 Bub A, Watzl B, Blockhaus M, Brivida K, Liegibel U, Müller H, et al. Fruit juice consumption modulates antioxidative status, immune status and DNA damage. Journal of Nutritional Biochemistry 2003; 14: 90-8.

25 Sánchez-Moreno C, Cano MP, de Ancos B, Olmedilla B, Granado F, Martín A. Effect of orange juice intake on vitamin $\mathrm{C}$ concentrations and biomarkers of antioxidant status in humans. American Journal of Clinical Nutrition 2003; 78 : 454-60.

26 Harats D, Chevion S, Nahir M, Norman Y, Sagee O, Berry E. Citrus fruit supplementation reduces lipoprotein oxidation in young men ingesting a diet high in saturated fat: presumptive evidence for an interaction between vitamins $\mathrm{C}$ and $\mathrm{E}$ in vivo. American Journal of Clinical Nutrition 1998; 67: $240-5$.

27 Kurowska EM, Spence D, Jordan J, Wetmore S, Freeman DJ, Piché LA, et al. HDL-cholesterol-raising effect of orange juice in subjects with hypercholesterolemia. American Journal of Clinical Nutrition 2000; 72: 1095-100.

28 Treiman K, Freimuth V, Damron D, Lasswell A, Anliker J, Havas S, et al. Attitudes and behaviors related to fruits and vegetables among low-income women in the WIC Program. Journal of Nutrition Education 1996; 28: 149-56.

29 Anderson AS, Cox DN, McKellar S, Reynolds J, Lean MEJ, Mela DJ. Take Five, a nutrition education intervention to increase fruit and vegetable intakes: impact on attitudes towards dietary change. British Journal of Nutrition 1998; 80: $133-40$.

30 Taylor CA, Hampl JS, Johnston CSW. Low intakes of vegetables and fruits, especially citrus fruits, lead to inadequate vitamin $\mathrm{C}$ intakes among adults. European Journal of Clinical Nutrition 2000; 54: 573-8.

31 Anderson JV, Bybee DI, Brown RM, McLean DF, Garcia EM, Breer L, et al. Five A Day fruit and vegetable intervention improves consumption in a low income group. Journal of the American Dietetic Association 2001; 101: 195-202.

32 Zino S, Skeaff M, Williams S, Mann J. Randomised controlled trial of effect of fruit and vegetable consumption on plasma concentrations of lipids and antioxidants. British Medical Journal 1997; 314: 1787-91.

33 Broeksmans WMR, Klöpping-Ketelaars IAA, Schuurman CRWC, Verhagen H, van den Berg H, Kok F, et al. Fruits and vegetables increase plasma carotenoids and vitamins and decrease homocysteine in humans. Journal of Nutrition 2000; 130: 1578-83.

34 Block G, Norkus E, Hudes M, Mandel S, Helzlsouer K. Which plasma antioxidants are most related to fruit and vegetable consumption? American Journal of Epidemiology 2001; 154: $1113-8$ 